\title{
Carbon-nanoparticle-triggered acute lung inflammation and its resolution are not altered in PPAR $\gamma$-defective (P465L) mice
}

\author{
Alexander A Götz ${ }^{1 *}$, Antonio Vidal-Puig ${ }^{2}$, Heiko G Rödel ${ }^{3}$, Martin Hrabé de Angelis ${ }^{4}$ and Tobias Stoeger ${ }^{1 *}$
}

\begin{abstract}
Background: The alveolar macrophage (AM) - first line of innate immune defence against pathogens and environmental irritants - constitutively expresses peroxisome-proliferator activated receptor $\gamma$ (PPAR $\gamma$ ). PPAR $\gamma$ ligandinduced activation keeps the AM quiescent, and thereby contributes to combat invaders and resolve inflammation by augmenting the phagocytosis of apoptotic neutrophils and inhibiting an excessive expression of inflammatory genes. Because of these presumed anti-inflammatory functions of PPARr we tested the hypothesis, whether reduced functional receptor availability in mutant mice resulted in increased cellular and molecular inflammatory response during acute inflammation and/or in an impairment of its resolution.

Methods: To address this hypothesis we examined the effects of a carbon-nanoparticle (CNP) lung challenge, as surrogate for non-infectious environmental irritants, in a murine model carrying a dominant-negative point mutation in the ligand-binding domain of PPARy (P465L/wt). Animals were instilled intratracheally with Printex 90 CNPs and bronchoalveolar lavage (BAL) was gained $24 \mathrm{~h}$ or $72 \mathrm{~h}$ after instillation to investigate its cellular and protein composition.
\end{abstract}

Results: Higher BAL cell numbers - due to higher macrophage counts - were found in mutants irrespective of treatment. Neutrophil numbers in contrast were slightly lower in mutants. Intratracheal CNP instillation resulted in a profound recruitment of inflammatory neutrophils into the alveolus, but genotype related differences at acute inflammation (24 h) and resolution (72 h) were not observed. There were no signs for increased alveolar-capillary membrane damage or necrotic cell death in mutants as determined by BAL protein and lactate-dehydrogenase content. Pro-inflammatory macrophage-derived cytokine osteopontin was higher, but galectin-3 lower in female mutants. CXCL5 and lipocalin-2 markers, attributed to epithelial cell stimulation did not differ.

Conclusions: Despite general genotype-related differences, we had to reject our hypothesis of an increased CNP induced lung inflammation and an impairment of its resolution in PPARy defective mice. Although earlier studies showed ligand-induced activation of nuclear receptor PPARy to promote resolution of lung inflammation, its reduced activity did not provide signs of resolution impairment in the settings investigated here.

Keywords: peroxisome-proliverator activated receptor $\gamma$, carbon-nano particle, pulmonary inflammation, chronic lung disease, challenge, immune cell, broncho-alveolar lavage (BAL), inflammatory marker

\footnotetext{
* Correspondence: alexander.a.goetz@web.de; tobias.stoeger@helmholtzmuenchen.de

${ }^{1}$ Comprehensive Pneumology Center, Institute of Lung Biology and Disease, Helmholtz Zentrum München, German Research Center for Environmental Health, Ingolstaedter Landstrasse 1, Neuherberg/Munich, D-85764, Germany Full list of author information is available at the end of the article
} 


\section{Background}

The peroxisome proliferator-activated receptor $\gamma(\operatorname{PPAR} \gamma)$ is expressed in several organs and tissues [1-3] and is involved in the regulation of adipocyte differentiation and glucose homeostasis [4-7], being a regulator of energy homeostasis. PPAR $\gamma$ has been involved in lung maturation in mice $[3,8]$ and its expression was found in immune cells, like lymphocytes, macrophages, and granulocytes, the latter mainly involved in inflammatory reactions $[9,10]$. PPAR $\gamma$ acts as a ligand-activated transcription factor [11]. Prostaglandins [8,12], but also synthetic and nonsteroidal anti-inflammatory substances $[8,13]$ activate the receptor. PPAR $\gamma$ activation has been shown to exhibit anti-inflammatory potential by inhibiting the activity of pro-inflammatory transcription factors such as e.g. the activator protein 1 (AP-1), signal transducer and activators of transcription (STATs), or the Nuclear factor kappa B $(\mathrm{NF}-\kappa \mathrm{B})$, as shown in murine primary peritoneal macrophages [14-16].

In particular alveolar macrophages (AM) have increased levels of PPAR $\gamma$ [9] and are constantly bathed in lipid-rich surfactant [17] that consists of potential receptor activating ligands, or at least precursors of ligands $[14,18,19]$. This coexistence of high levels of PPAR $\gamma$ in an environment rich in lipophilic ligands is an important finding, since: i) resident AMs in the alveolus represent the first line of innate immune defence in the respiratory tract and ii) AM orchestrate inflammatory responses by recognizing tissue damage, promoting neutrophil recruitment for appropriate pathogen defence and finally leading to resolution of inflammation [20]. This indispensable role in lung homeostasis makes the AM a promising target for the treatment of inflammatory lung diseases. In fact murine studies have revealed AM function requires upregulation of the expression of CD36, a PPAR $\gamma$ target. CD36 is a cell surface scavenger receptor and a key factor promoting phagocytosis of apoptotic neutrophils, lipids and unopsonized materials [18]. Similarly, an increase in Fc $\gamma$ receptor mediated phagocytosis of opsonized materials [21] seems to require PPAR $\gamma$ activation. This AM cell-mediated effector promoting resolution of inflammation depends on the PPAR $\gamma$-induced molecular anti-inflammatory properties [22] as well as by factors of different lung structural cell types, thereby down-regulating pro-inflammatory mediators [10] like TNF $\alpha$, neutrophil and monocyte-macrophage chemotactic factors IL-8, MCP-1, pro-oxidant enzyme iNOS, and MMP9 [23-25] while up-regulating expression of anti-inflammatory proteins like IL-10 (reviewed in [9]). These results suggest a potential therapeutic application of PPAR $\gamma$ activation to resolve lung inflammatory disorders. This is particularly relevant since AM play a critical role in pathogenesis of asthma, chronic obstructive pulmonary disease (COPD), lung fibrosis (IPF) and lung sarcoidosis (for review see [9]). Moreover PPAR $\gamma$ binding to the respective response elements in AMs is markedly reduced in chronic inflammatory pulmonary sarcoidosis and obstructive diseases [26,27]. This suggests that the alveolar microenvironment might be immunosuppressive in the absence of a specific stimulus [28], keeping the AM in a quiescent mode possibly supported by PPAR $\gamma$ function.

PPAR $\gamma$ knockout models have already revealed developmental airspace enlargement, and greater smoke-induced emphysema, with increased AM numbers $[3,8]$. In agreement with this beneficial effects of ligand-induced PPAR $\gamma$ activation in the lung $[8,29]$ have been suggested, as indicated by the attenuation of pro-inflammatory cytokine release from activated AMs, eosinophils and type2 epithelial cells [29], and reduced smoke-induced epithelial mucin production [30]. Improved pathophysiological states in models for asthma, COPD, IPF, and acute lung injury have also been found [29,31-33]. In contrast, PPAR $\gamma$ deficiency or lack of receptor activation in macrophages resulted in increased atherosclerosis [34] and reduced CD36 expression [18,35]. Take together all together, these findings highlight PPAR $\gamma$ as a promising target for the treatment of many inflammatory pathologies by promoting resolution of inflammation [18].

According to these anti-inflammatory effects in the lung and the fact that unresolved pulmonary inflammation may lead to chronic disease states, we tested the hypothesis that a diminished PPAR $\gamma$ function may result in an increased cellular and molecular inflammatory response, during acute inflammation and impaired resolution. With regard to an inflammatory stimulation of the lungs by particulate matter, so far PPAR $\gamma$ function has only been associated with exposure to cigarette smoke but not with environmental particles such as combustion derived nanoparticles. To address this hypothesis we investigated mice (C57BL/6J) carrying a dominantnegative point mutation (P465L) in the ligand-binding domain of the PPAR $\gamma$ receptor - a targeted mutation, equivalent to a rare mutation in humans (P467L) [5,36-38]. Whereas human carriers of the mutation suffer from lipodystrophy, extreme insulin resistance, as well as hypertension, fatty liver, and lower adiponectin levels in circulation, humans with the homozygous for P465L die in utero. Mice with the same mutation developed apparently morphologically normal total amounts of adipose tissue - although displaying higher extra-abdominal fat mass - and were insulin sensitive [6,7]. However, these animals recapitulated the human phenotype once challenged with positive energy balance [7]. We favoured to use P465L/wt mutant mice over the more severely compromised PPAR $\gamma$ knock-out mice since it more reliably resembles the situation in chronic inflammatory lung 
diseases as described, in alveolar macrophages - like in asthma [39], pulmonary sarcoidosis [26,27] and COPD [9] - or in epithelial cells like in cystic fibrosis [40], where PPAR $\gamma$ activation was found to be reduced, but not absent. Our rational was that if PPAR $\gamma$ contributes to an anti-inflammatory macrophage state and/or is involved in the resolution of inflammation, then PPAR $\gamma$ defective mice should show impaired resolution of particle induced lung inflammation, a model clearly involving alveolar macrophage function $[41,42]$.

To our knowledge, apart from cigarette smoke, yet no one has investigated PPAR $\gamma$ related effects in the context of particle related lung inflammation. Exposure to Printex 90 was primarily chosen as a surrogate for urban air pollution by combustion derived nanoparticles. However since in addition to its generation by combustion processes like from diesel engines, carbon black is a constituent of lots of products of modern societies, like inks and paints, rubber and plastic, and thus progressively becoming a more relevant anthropogenic source of ambient and indoor particulate matter. In fact more than 10 million tones are produced every year [43]. But regardless of CNP ancestry, whether airborne, combustion derived or engineered, this sub-100 nm scaled particle class has gained toxicological interest due to their small dimensions, large surface area and high deposition efficiency in the lung being considered an important driver of adverse health effects linked to respiratory toxicity $[44,45]$. It is widely accepted that particulate air pollution contributes to the adverse health effects in humans and that patients with metabolic syndrome (obesity, hypertension and diabetes mellitus) may be a more susceptible population. Thus the identification of underlying pathways linking the inflammatory responses induced by particle related health effects and susceptibility to metabolic diseases are of prime importance. In this respect we speculate that PPAR $\gamma$ might be one of the connections linking the regulation of lipid metabolism with alveolar inflammation.

In summary our aim was on to contribute to the understanding of the pathogenic role of PPAR $\gamma$ biology during pulmonary inflammation caused by non-infectious respirable stimuli as represented by carbonaceous particulate matter. We wanted to clarify whether the reduced availability of functional PPAR $\gamma$ in (P465L/wt) mutant mice increased the susceptibility towards acute inflammation and failed resolution in response to CNP-stimulus in comparison to PPAR $\gamma$ wild-type mice (wt/wt). Experiments were performed in adult, 12-14 weeks old, PPAR $\gamma$ wildtype (wt/wt) and P465L/wt mutant mice of both genders to account for sex-specific hormone levels $[46,47]$. Animals were challenged using physically and chemically well characterized CNPs of moderate toxicity as described earlier [41].

\section{Results}

\section{Bronchoalveolar Lavage (BAL) cell analysis}

Bronchoalveolar lavage (BAL) volumes obtained from age- and body mass-matched PPAR $\gamma$ wild-type (wt/wt) and PPAR $\gamma$ mutant mice (P465L/wt) did not reveal significant differences between groups allowing an adequate comparison of BAL cell differentials between groups. Cytospin analysis showed significant differences in total BAL cell numbers between genotypes. This was observed in both sexes, being generally slightly higher in the mutant group irrespectively of the treatment (Figure 1A and $1 \mathrm{E})$. This effect was due to higher macrophage counts associated with the mutant genotype (Figure $1 \mathrm{~B}$ and $1 F)$. In contrast the BAL neutrophil pool was lightly lower in mutants (Figure $1 \mathrm{C}$ and $1 \mathrm{G}$ ). Lymphocyte numbers did not differ between genotypes in both sexes (Figure 1D and $1 \mathrm{H}$ ). Significant interaction terms (treatment $\times$ sex) indicated some sex-specific differences. Compared to males, females displayed lower total BAL cell numbers under control conditions but higher numbers at the $72 \mathrm{~h}$ time point. This difference was mainly reflected by initially (HCC condition) lower macrophage numbers (Figure 1B and 1F, Additional File 1, Figure s4 B) and higher numbers of macrophages at the $72 \mathrm{~h}$ time point (Figure 1D and 1H, Additional File 1, Figure s4). In male mice total BAL cell numbers where constant and not affected by the treatment (Figure $1 \mathrm{~A}$ and $1 \mathrm{E}$; Additional File 1, Figure s4 A). No sex-specific effect of treatment was observed for BAL neutrophil numbers (Figure 1C and 1G, Additional File 1, Figure s4 C), being considered the most significant read out for inflammation.

Especially the absence of neutrophils in all HCC groups (Figure $1 \mathrm{C}$ and $1 \mathrm{G}$ ) was evidencing that there was no pro-inflammatory condition, in absence of a treatment related stimulus. Twenty-four hours after particle instillation (CNP-24 h), a significant influx of neutrophil granulocytes into the alveolar lumen was observed, indicating acute lung inflammation in both, wild-type and mutant animals (Figure $1 \mathrm{C}$ and $1 \mathrm{G}$ ). However, particle instillation did not cause significant genotype-related differences in the magnitude of neutrophil recruitment into alveolar lumen (Figure 1C and 1G). Seventy-two hours after particle instillation (CNP-72 h) neutrophil numbers were significantly lower in comparison to the time point of acute lung inflammation (CNP-24 h), indicating similar degree of resolution of inflammation on a cellular level in both genotypes and sexes (Figure 1C and 1G).

\section{BAL: Protein and Lactate Dehydrogenase (LDH)}

Consistent with the absence of any difference in the cellular component of the inflammation we did not observe differences in the alveolar-capillary barrier function and 

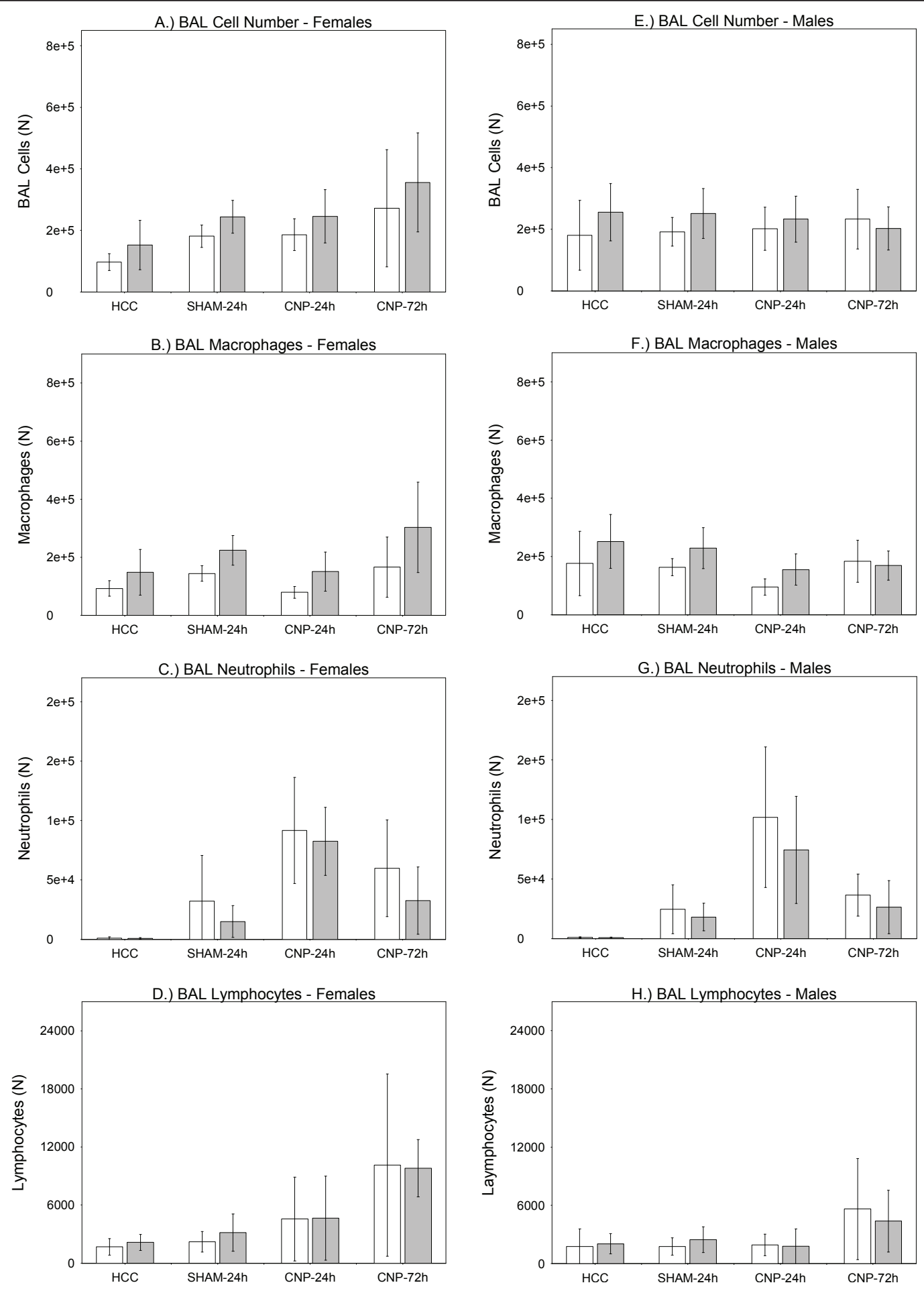

Figure 1 Bronchoalveolar lavage (BAL) cell differentials. BAL cells of female (A.-D.) and male (E.-H) PPARy wild-type (wt/wt) (white bars) and PPARy mutant mice (P465L/wt) (grey bars). Untreated home cage controls (HCC); water-instilled animals at $24 \mathrm{~h}$ time point (SHAM-24 h); particle-instilled mice at $24 \mathrm{~h}$ (CNP-24 h) and $72 \mathrm{~h}$ time point (CNP-72 h). For sample size, please see Table1. Statistics: General Linear Model (GLM): BAL Cell Number: genotype: $F / W=11.045, d f=1,{ }^{* *} P=0.001$; treatment: $F / W=12.254, d f=3,{ }^{* * *} P<0.001$; sex: ${ }^{* * *} P<0.001$; treatment $\times$ sex: $F M=6.449, d f=3,{ }^{* * *} P<0.001 ;$ BAL Macrophages: genotype: $F M=29.434, d f=1,{ }^{* *} P<0.001 ;$ treatment: $F M=9.767, d f=3,{ }^{* *} P<0.001 ;$ sex: $F M=14.869, d f=1,{ }^{* * *} P<0.001 ;$ treatment $\times$ sex: $F M=4.697, d f=3,{ }^{* * P}=0.0039 ; B A L$ Neutrophils: genotype: $F / W=7.274, d f=1, * * P=0.008 ;$ treatment: $F / W=103.631, d f=3,{ }^{* * *} P<0.001$; sex: $F / W=0.892, d f=1, P=0.347 ; B A L$ Lymphocytes: genotype: $F / W=0.352, d f=1, P=0.5543$; treatment: $F W=17.437, d f=3,{ }^{* *} P<0.001$; sex: $F M=0.059, d f=1, P=0.810$; treatment $\times$ sex: $F / W=2.944,{ }^{*} P=0.036$; 
found no indications of increased lung injury in the mutant mice, as usually indicated by increased BAL protein. Total BAL protein content did not differ between PPAR $\gamma(w t / w t)$ and PPAR $\gamma($ P465L/wt) mice of both sexes under untreated HCC, SHAM, and CNP conditions after $24 \mathrm{~h}$ and $72 \mathrm{~h}$ (Additional File 1, Figure s1 A and $\mathrm{C}$ ), respectively. This agreed with the fact that concentrations of the intracellular enzyme $\mathrm{LDH}$ in $\mathrm{BAL}$ supernatant were not different between HCC groups. Also no differences were observed in LDH levels 24 hours or 72 hours after particle instillation between genotypes (Additional File 1, Figure s1 B and D). All together, this shows lack of differences in cell membrane damage and necrotic cell death in BAL cells between genotypes.

\section{BAL Inflammatory marker (ELISA)}

Given that the cellular extent of inflammation was not different between genotypes we next searched for molecular differences in BAL inflammatory markers. We selected four pro-inflammatory proteins known to be induced by carbon-nanoparticle treatment as shown before $[42,48]$ or known for their inflammatory/neutrophil recruiting properties. To be able to localize the response of particular cell populations we measured galectin-3 (GAL3) and osteopontin (SPP1), as predominantly alveolar macrophage derived cytokines (Figure $2 \mathrm{~A}$ and $2 \mathrm{~B}$ ). To determine the inflammatory status of the epithelium in response to CNP instillation we investigated the BAL concentrations of anti-bacterial lipocalin-2 (LCN2/NAGL) and neutrophil recruiting cytokine CXCL5 (Figure 3A and 3B). This determination was performed in female mice only.
Analysis of alveolar macrophage derived Gal3 concentrations in BAL fluid of female PPAR $\gamma$ (P465L/wt) mutant mice revealed lower levels in comparison to PPAR $\gamma$ wild-type females (wt/wt) (GLM) under all treatment conditions (Figure 2A). In contrast, the opposite was observed for SPP1, its concentration being higher for all treatment conditions in PPAR $\gamma(\mathrm{P} 465 \mathrm{~L} / \mathrm{wt})$ mutant mice in comparison with wild-type (Figure 2B). Concerning epithelial derived BAL CXCL5 and BAL lipocalin-2 no difference between genotypes was observed under whatever condition tested (Figure 3A and 3B). Values for BAL lipocalin-2 were markedly induced by particle treatment in both genotypes as indicated at $24 \mathrm{~h}$ time point, and were declining at $72 \mathrm{~h}$ time point.

\section{Haematological Analysis - Systemic Activation of Blood Leukocytes}

Since no differences were found dependent on genotypes, gender (HCC) and treatments (SHAM; CNP-24 h; CNP$72 \mathrm{~h}$ ) as far as BAL cell populations were concerned, we next set to investigate whether PPAR $\gamma$ mutations may affect the recruitment of immuno-competent leukocytes into the blood stream. Blood cell analysis did not reveal any difference at all between wild type (wt/wt) and PPAR $\gamma(\mathrm{P} 465 \mathrm{~L} / \mathrm{wt})$ in both sexes, neither for total white blood cells (WBC), nor there was a difference in leukocyte subpopulations; lymphocyte, monocyte and granulocyte numbers (neutrophils, eosinophils, and basophils) (Additional File 1, Figure s2 and s3).

\section{Discussion}

The point mutation P467L in human receptor PPAR $\gamma$ has been shown to be associated with adverse effects for

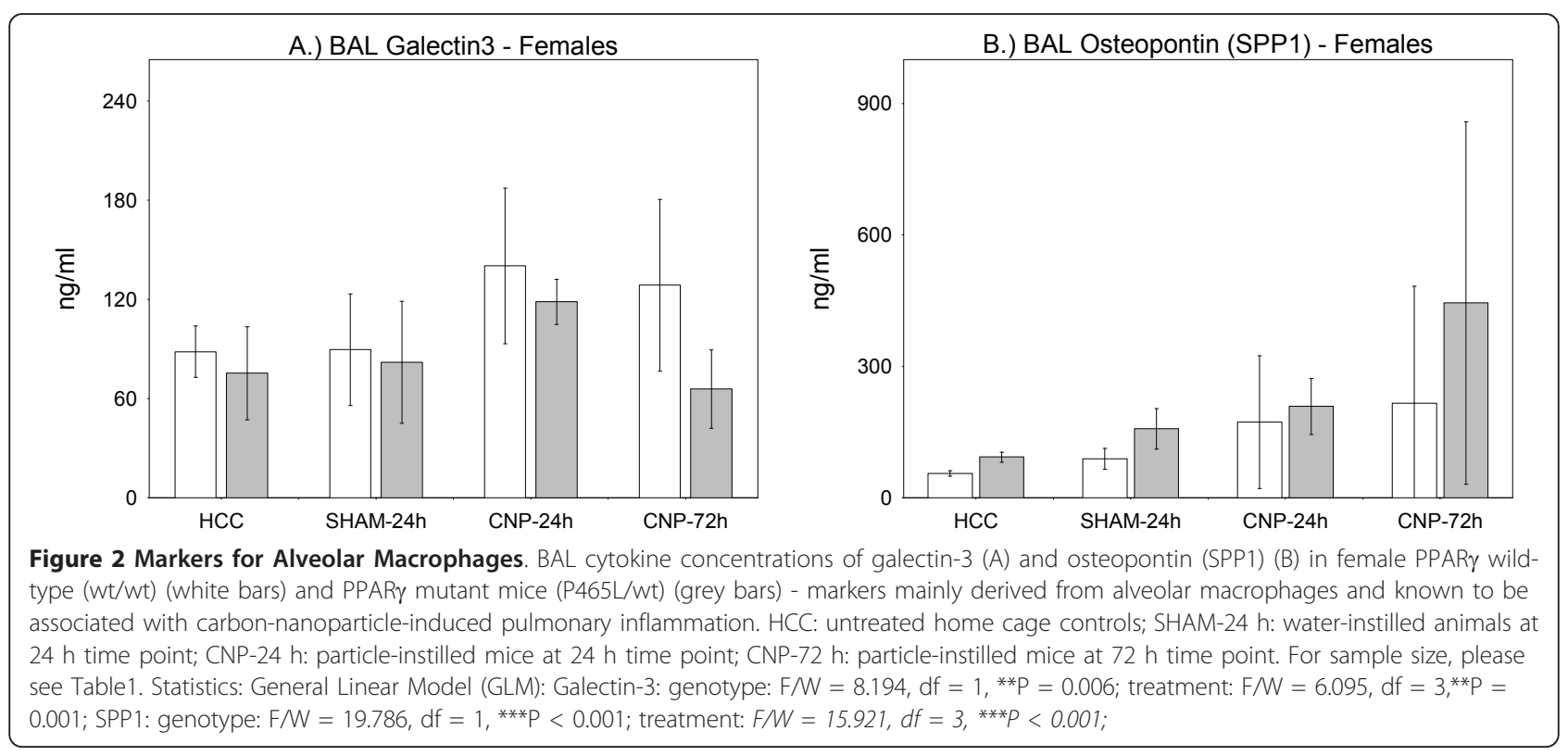


A.) BAL CXCL5 (LIX) - Females

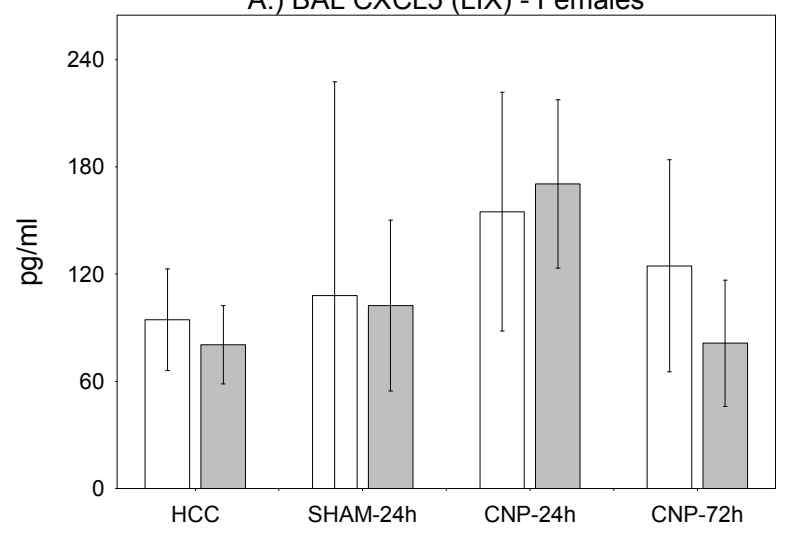

B.) BAL Lipocalin2 (NGAL) - Females

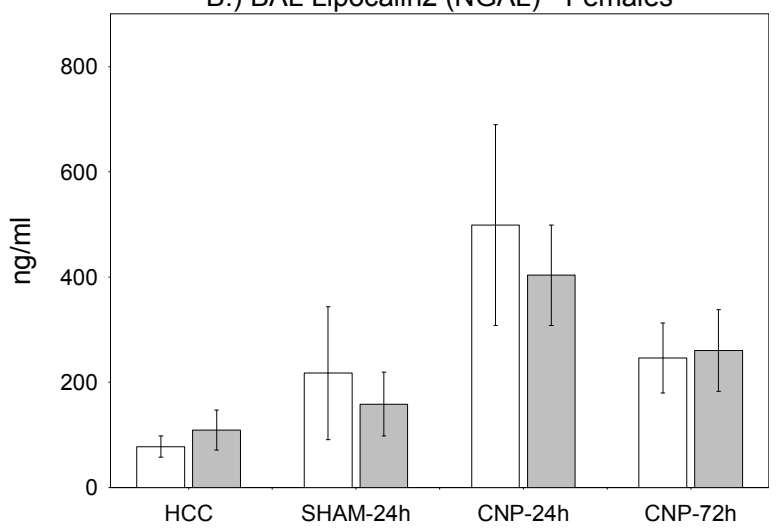

Figure 3 Markers for Epithelial Cells. BAL cytokine concentrations of CXCL5 (A), and lipocalin-2 (B) in female PPAR $\gamma$ wild-type (wt/wt) (white bars) and PPARy mutant mice (P465L/wt) (grey bars) - markers mainly derived from lung epithelium, and known to be associated with carbonnanoparticle-induced pulmonary inflammation. HCC: untreated home cage controls; SHAM-24 h: water-instilled animals at 24 h time point; CNP24 h: particle-instilled mice at $24 \mathrm{~h}$ time point; CNP-72 h: particle-instilled mice at $72 \mathrm{~h}$ time point. For sample size, please see Table1. Statistics: General Linear Model (GLM): CXCL5: genotype: $F / W=0.205, d f=1,{ }^{*} P=0.6524$; treatment: $F / W=5.334, d f=3,{ }^{* *} P=0.003 ;$ lipocalin-2: genotype: $F / W=0.007, d f=1, P<0.9348$; treatment: $F / W=56.810, d f=3,{ }^{* *} P<0.001$;

human health and well-being, resulting in lipodystrophy, severe insulin resistance, fatty liver, hypertension, and lowered adiponectin levels in circulation [5]. In regard to this specific human situation, mice carrying a targeted point mutation in the ligand-binding domain of PPAR $\gamma$ (P465L), being the equivalent mutation to human P467L, were generated as an animal model, which partially confirmed the effects described in humans particularly when confronted to extreme metabolic challenges [6,7]. We used sex-, age-, and body mass-matched PPAR $\gamma$ mutant mice (P465L/wt) to investigate the receptor role in a particle-induced model of aseptic acute lung inflammation.

Here we show PPAR $\gamma$ genotype-related differences in total BAL cell numbers, with increased macrophages and reduced neutrophil counts in mutant mice. In addition, our BAL data may also indicate a pro-inflammatory shift of the M1/M2 balance of alveolar macrophages, since (i) generally higher BAL osteopontin values in mutant mice point towards a more pro-inflammatory, M1 polarized macrophage condition, and (ii) lower galectin-3 values - a marker for alternative macrophage activation - in turn indicate reduced M2 polarization. However although alternative macrophage activation is regarded as a PPAR $\gamma$ driven process, relevant for the resolution of inflammation, our data can not support the impact of PPAR $\gamma$ signalling on particle elicited lung inflammation. Our study in fact rather demonstrates that an insult with carbonnanoparticle (CNP) challenge, administered by intratracheal instillation of Printex 90 particles to the lungs of mutant $\mathrm{P} 465 \mathrm{~L} / \mathrm{wt}$ and wild-type mice $(\mathrm{wt} / \mathrm{wt}$ ) produces a similar extend of inflammatory cell recruitment during acute inflammation and resolution. That implies that the course of inflammation assessed in our lung inflammation model was not affected at cellular level by the suspected macrophage unbalance in $\mathrm{P} 465 \mathrm{~L} / \mathrm{wt}$ mice.

Though the inflammatory reaction provoked by CNPs was mild as compared with experimental endotoxin models for instance, the response to CNP still might have been robust enough to overwhelm PPAR $\gamma$ pathways, and thus mask P465L/wt impairments. We have chosen an intratracheally delivered dose of $20 \mu \mathrm{g}$ CNP, which as already previously described [41,42], resulted in marked recruitment of inflammatory cells into the alveolar lumen, without provoking significant epithelial injury. Accordingly BAL protein and BAL lactate-dehydrogenase (LDH) levels, indicators of acute lung injury and cell necrosis, did not show biologically relevant increases. The dose of $20 \mu \mathrm{g}$ carbon particles used here represents a surface area dose of $54 \mathrm{~cm}^{2}$ per mouse, an area previously related to the surface burden affected within months of people living in high polluted areas [41]. The time points of $24 \mathrm{~h}$ acute response phase and $72 \mathrm{~h}$ resolution phase are well suited to investigate the proposed hypothesis, since our results are in line with an earlier study using the same challenge design (same stimulus and dose), showing most of inflammatory neutrophil clearance in BAL fluid $72 \mathrm{~h}$ after challenge [42].

We can speculate that the P465L related disturbance might be limited to the macrophages, and not directly involve the epithelia compartment. P465L/wt conditions seem not effective to exacerbate/prevent the initiation or resolution of a moderate but robust, aseptic, and neutrophilic inflammation. Accordingly the epithelial-derived inflammatory marker proteins CXCL5 and lipocalin-2 did not differ between genotypes at any time point. Blood 
leukocyte numbers where also not affected by genotype, and did not reveal any signs for systemic inflammation upon CNP treatment. The lack of genotype related blood cell differences contrasts with the observed P465L related differences in BAL cell numbers/BAL macrophages and points towards the predominant importance of PPAR $\gamma$ in the alveolar region, without exhibiting systemic effects.

The absence of genotype-related differences in the cellular CNP-driven acute lung inflammation and its resolution may also be based on the possibility that $\mathrm{P} 465 \mathrm{~L}$ heterozygous mutant mice have been able to activate their mutant receptor, a possibility that may occur if high concentrations of the ligands are available. In fact it was previously shown for the respective human mutation, that increased ligand-concentrations are able to rescue the partial receptor deficit [49]. High ligand-concentrations are well conceivable for the lipid rich alveolar lining fluid presenting the direct environment of alveolar macrophages. Under this assumption future investigation would have to use a functional null of PPAR $\gamma$ in alveolar macrophages.

Compensation at the genomic level by an upregulation of wt-PPAR $\gamma$ expression in $\mathrm{P} 465 \mathrm{~L} / \mathrm{wt}$ macrophages is not likely, since the PPAR $\gamma$ expression level in mutant BAL macrophages is very similar to that of wt mice $(120 \pm 10 \%$ of wt).

The conserved pattern of co-activator molecules used for the function of different PPARs would have been expected to contribute to a more pro-inflammatory condition in the alveolar compartment, but basal BAL levels of classically pro-inflammatory cytokines such like TNF $\alpha$ revealed unchanged in wt versus mutant mice (data not shown). In this context the lack of a proinflammatory status in blood system as well as in the alveolar compartment shows that the organism in whole can cope with the challenge even under the mutant PPAR $\gamma$ condition. We regard a lack of an increased proinflammatory situation in mutants to be related to the lipid-rich environment of the macrophage within the alveolar lining fluid, which may have compensated for a loss of receptor functionality [49].

\section{Conclusions}

Our data contribute to the understanding of PPAR $\gamma$ receptor relevance in the context of alveolar macrophage biology during lung inflammation or particular resolution. In contrast to the by Asada 2004 suggested proresolving activity of PPAR $\gamma$ [18] during clearance of apoptotic neutrophils, no changes were found related to the function of this specific dominant-negative PPAR $\gamma$ point mutation. In order to further address and clarify the receptor's specific role in the AM-mediated resolution of pulmonary inflammation and its possible as well as suggested role in the transition towards chronic lung disease, we emphasize the need for further investigations, particularly by using macrophage specific PPAR $\gamma$ knockout models.

\section{Methods}

\section{Animal Generation and Genotyping}

P465L/wt mutant mice were generated and genotyped as described earlier in $[7,50]$. P465L/wt mice where obtained from the University of Cambridge (UK) on a mixed C57BL/6-129/SvJ background and backcrossed for 9 generations to $\mathrm{C} 57 \mathrm{BL} / 6 \mathrm{~J}$ for isogenicity.

\section{Particle Challenge Design and Group Setup}

Animals were either instilled with aqueous suspension (zeta potential: $33 \mathrm{mV}$; agglomerate diameter in suspension: $0.17 \mu \mathrm{m}$ ) of Printex90 carbon-nanoparticles (CNP), a commercially available pigment black from Degussa (Frankfurt, Germany), (diameter [nm]: 14; organic content [\%]: 1 ; surface area $\left.\left[\mathrm{m}^{2} / \mathrm{g}\right]: 272\right)$; as described earlier in [42]), or pyrogene-free distilled water (SHAM exposed) respectively or were left undisturbed and served as controls (Home Cage Control; HCC). For details on group setup and sample size, see table 1 ;

Prior to instillation, mice were anesthetized by intraperitoneal injection of a mixture of Medetomidin ( $0.5 \mathrm{mg} / \mathrm{kg}$ body mass), Midazolam $(5.0 \mathrm{mg} / \mathrm{kg}$ body mass) and Fentanyl ( $0.05 \mathrm{mg} / \mathrm{kg}$ body mass). The animals were then intubated by a nonsurgical technique [51]. Using a cannula inserted $10 \mathrm{~mm}$ into the trachea, a suspension containing $20 \mu \mathrm{g}$ CNPs, respectively, in $50 \mu \mathrm{l}$ pyrogene-free distilled water was instilled, followed by $100 \mu \mathrm{l}$ air; the suspension of poorly soluble CNPs was sonicated on ice for $1 \mathrm{~min}$ prior to instillation, using a SonoPlus HD70 (Bachofer, Berlin, Germany) at a moderate energy of $20 \mathrm{~W}$. SHAM animals were instilled $50 \mu \mathrm{l}$ pyrogene-free distilled water only [41]. After instillation animals were antagonized by subcutaneous injection of a mixture of Atipamezol ( $2.5 \mathrm{mg} / \mathrm{kg}$ body mass), Flumazenil $(0.5 \mathrm{mg} / \mathrm{kg}$ body mass $)$ and Naloxon $(1.2 \mathrm{mg} / \mathrm{kg}$ body mass) to guarantee their awakening and well-being. Animals were treated humanely and with regard for alleviation of suffering; experimental protocols were reviewed and approved by the Bavarian Animal Research Authority.

\section{Blood, Serum, and Bronchoalveolar Lavage (BAL) sampling}

Twenty-four hours or seventy-two hours after instillation, mice were anesthetized by intraperitoneal injection of a mixture of xylazine $(4.1 \mathrm{mg} / \mathrm{kg}$ body weight) and ketamine ( $188.3 \mathrm{mg} / \mathrm{kg}$ body weight) and killed by exsanguination. Therefore blood was drawn from the retroorbital 
Table 1 Group Setup and treatment

\begin{tabular}{ccccc}
\hline Group & Home Cage Control (HCC) & $\begin{array}{c}\text { H20 - 24 h } \\
\text { (SHAM) }\end{array}$ & $\begin{array}{c}\text { Printex90 - 24 h } \\
\text { (CNP-24 h) }\end{array}$ & $\begin{array}{c}\text { Printex90 - 72 h } \\
\text { (CNP-72 h) }\end{array}$ \\
\hline Male PPARy +/+ & 7 & 6 & 7 & 6 \\
Male PPARy P465L/wt & 9 & 8 & 11 & 10 \\
Female PPAR $+/+$ & 8 & 6 & 7 & 7 \\
Female PPARy P465L/wt & 9 & 9 & 8 & 6 \\
\hline
\end{tabular}

Group Setup and treatment of investigated male and female wild-type (wt/wt) and PPAR $\gamma$ mutant mice (P465L/wt). Numbers of animals investigated per group are provided.

plexus by a capillary and collected a.) in EDTA covered tubes (Sarstedt) for haematological analysis (ADVIA Hematology Systems (Bayer Diagnostics) and b.) non EDTA-covered tubes to gain blood serum. Subsequently BAL was performed by cannulating the trachea and infusing the lungs 4 times with $1.0 \mathrm{ml}$ PBS without calcium and magnesium, in adaptation as described previously [41]. The BAL fluids from lavages 1 and 2 and from lavages 3 and 4 were pooled and centrifuged ( $425 \mathrm{~g}$, $20 \mathrm{~min}$ at room temperature). The cell-free supernatant from lavages 1 and 2 were used for biochemical measurements such as lactate dehydrogenase (LDH), total protein, and cytokine concentrations. The cell pellet was resuspended in $1 \mathrm{ml}$ RPMI 1640 medium (BioChrome, Berlin, Germany) and supplemented with $10 \%$ fetal calf serum (Seromed, Berlin, Germany); the number of living cells was determined by the trypan blue exclusion method. We performed cell differentials on the cytocentrifuge preparations (May-Grünwald- Giemsa staining; $2 \times 200$ cells counted) and the number of polymorphonuclear leukocytes (PMNs) was used as a marker of inflammation.

\section{BAL: Total Protein Content and Lactate Dehydrogenase (LDH) Assay}

Total BAL protein content was determined spectrophotometrically with an ELISA reader (Labsystems iEMSReader MF, Helsinki, Finland) at $620 \mathrm{~nm}$, applying the Bio-Rad Protein Assay Dye Reagent (no. 500-0006; BioRad, Munich, Germany), as a potential biological marker for pulmonary capillary leakage and lung injury [52]. $5 \mu \mathrm{l} \mathrm{BAL} \mathrm{fluid/mouse} \mathrm{was} \mathrm{used} \mathrm{for} \mathrm{analysis.}$

For detection of the cytosolic enzyme lactate dehydrogenase $(\mathrm{LDH})(\mathrm{U} / \mathrm{ml})$, characteristic for membrane damaging effects, the Cytotoxicity Detection Kit (Roche Diagnostics, Germany) was used according to the manufacturer's instructions. LDH concentration in the BAL fluid $(30 \mu \mathrm{l})$ was spectrophotometrically determined with an ELISA reader (Labsystems iEMS Reader MF, Helsinki, Finland) at a wavelength of $492 \mathrm{~nm}$.

\section{BAL Cytokine Detection (ELISA)}

The characteristic carbon-nanoparticle (CNP) induced alveolar macrophage inflammatory markers osteopontin
(SPP1) (mouse Osteopontin; R\&D Duo Sets; Catalog Number: DY441) and galectin-3 (mouse Galectin-3; R\&D Duo Sets; Catalog Number: DY1197) [48], as well as the known lung mainly epithelial derived inflammatory markers LIX (CXCL5) (mouse LIX; R\&D Duo Sets; Catalog Number: DY443), and lipocalin-2 (NGAL), (mouse Lipocalin-2/NGAL; R\&D Duo Sets; Catalog Number: DY1857) [42,48] were assayed from BAL samples using the respective ELISA kit. One hundred $\mu \mathrm{l}$ of appropriate BAL fluid dilutions were used. Dilutions were: SPP1: 1:100; galectin-3: 1:100; lipocalin-2: 1:400; LIX: undiluted.

\section{Statistics}

We tested the effects of the factors genotype (2 levels: wild-type (wt/wt) and mutant (P465L/wt), sex (2 levels: male, female) and treatment (4 levels: untreated home cage control (HCC), water-instilled SHAM group at 24 hours (SHAM), carbon-nanoparticle exposure at time point 24 hours (CNP-24 h), carbon-nanoparticle exposure at time point 72 hours (CNP-72 h) on different response variables by the use of a general linear model design (GLM).

We included the 2-way interaction terms of the factors (genotype $\times$ treatment, genotype $\times$ sex, sex $\times$ treatment), in order to test whether the treatment showed differential effects in relation to the different genotypes and sexes. If not statistically significant, the interaction term was reduced and the model was re-calculated. In none of the models investigated the interaction term genotype $\times$ treatment was significant $(\mathrm{P}>0.10)$. Response variables, which deviated from the normal distribution, were log-, or square-root-transformed. Normality of the model residuals was checked visually by normal probability plots and with the Shapiro-Wilk test, and we assured the homogeneity of variances and goodness of fit by plotting residuals versus fitted values and by the Levene test. In case of significant interaction terms, post-hoc comparisons were conducted with the Tukey test. All statistical analyses were done using the software SPSS 14.0 (SPSS Inc., Chicago, IL)

Significant P-values by GLM testing are provided in the figure legends by asterisks $\left({ }^{*} P<0.050 ;{ }^{*} P<0.010\right.$; *** $P<0.001)$. All data are expressed as mean \pm SEM. 


\section{Additional material}

Additional file 1: Additional Figures s1-s4 containing data of the Bronchoalveolar Lavage (BAL) protein and Lactate Dehydrogenase (LDH) content, blood cell differentials and showing sex-specific effects of treatment on BAL cell differentials.

\section{Acknowledgements}

The present work was supported by the German National Genome Research Network (NGFNplus 01GS0850). We would like to thank Birgit Frankenberger and David Kutschke for the excellent technical assistance.

\section{Author details}

'Comprehensive Pneumology Center, Institute of Lung Biology and Disease, Helmholtz Zentrum München, German Research Center for Environmental Health, Ingolstaedter Landstrasse 1, Neuherberg/Munich, D-85764, Germany. ${ }^{2}$ Metabolic Research Laboratories, Level 4, Institute of Metabolic Science, Box 289, NIHR Cambridge Biomedical Research Centre Addenbrooke's Hospital, University of Cambridge, Cambridge, CB2 OQQ, UK. ${ }^{3}$ Laboratory of Experimental and Comparative Ethology, University of Paris 13, F-93430, Villetaneuse, France. ${ }^{4}$ Institute of Experimental Genetics, Helmholtz Zentrum München, German Research Center for Environmental Health, Ingolstaedter Landstrasse 1, Neuherberg/Munich, D-85764, Germany.

\section{Authors' contributions}

AG and TS conceived and designed the experiments. AG performed the experiments and $A G$ and $H G R$ analyzed the data. AG, TS, HGR, MHA, and AVP wrote the manuscript. All authors read and approved the final manuscript.

\section{Competing interests}

The authors declare that they have no competing interests.

Received: 27 April 2011 Accepted: 20 September 2011

Published: 20 September 2011

\section{References}

1. Kliewer S, Forman B, Blumberg B, Ong E, Borgmeyer U, Mangelsdorf D, Umesono K, Evans RM: Differential expression and activation of a family of murine peroxisome proliferator-activated receptors. PNAS 1994, 91:7355-7359.

2. Lemberger T, Desvergne B, Wahli W: Peroxisome proliferator-activated receptors: a nuclear receptor signaling pathway in lipid physiology. ANNU REV CELL DEV BI 1996, 12:335-363.

3. Simon D, Arikan M, Srisuma Si, Bhattacharya S, Andalcio T, Shapiro S, Mariani TJ: Epithelial cell PPARgamma is an endogenous regulator of normal lung maturation and maintenance. POC AM THOR SOC 2006, 3:510-511.

4. Agarwal A, Garg A: A novel heterozygous mutation in peroxisome proliferator-activated receptor-gamma gene in a patient with familial partial lipodystrophy. J CLIN ENDOCR METAB 2002, 87:408-411.

5. Savage D, Tan G, Acerini C, Jebb S, Agostini M, Gurnell M, Williams R, Umpleby A, Thomas E, Bell J, et al: Human metabolic syndrome resulting from dominant-negative mutations in the nuclear receptor peroxisome proliferator-activated receptor-gamma. DIABETES 2003, 52:910-917.

6. Tsai Y, Kim H, Takahashi N, Kim H, Hagaman J, Kim J, Maeda N: Hypertension and abnormal fat distribution but not insulin resistance in mice with P465L PPARgamma. J CLIN INVEST 2004, 114:240-249.

7. Gray S, Dall Nora E, Grosse J, Manieri M, Stoeger T, Medina-Gomez G, Burling K, Wattler S, Russ A, Yeo G, et al: Leptin deficiency unmasks the deleterious effects of impaired peroxisome proliferator-activated receptor gamma function (P465L PPARgamma) in mice. DIABETES 2006, 55:2669-2677.

8. Belvisi M, Mitchell J: Targeting PPAR receptors in the airway for the treatment of inflammatory lung disease. BRIT J PHARMACO 2009, 158:994-1003
9. Becker J, Delayre-Orthez C, Frossard N, Pons F: Regulation of inflammation by PPARs: a future approach to treat lung inflammatory diseases? FUNDAM CLIN PHARM 2006, 20:429-447.

10. von Knethen A, Soller M, Brüne B: Peroxisome proliferator-activated receptor gamma (PPAR gamma) and sepsis. ARCH IMMUNOL THER EX 2007, 55:19-25

11. Spiegelman BM: PPAR-gamma: adipogenic regulator and thiazolidinedione receptor. DIABETES 1998, 47:507-514.

12. Reginato M, Krakow S, Bailey S, Lazar M: Prostaglandins promote and block adipogenesis through opposing effects on peroxisome proliferator-activated receptor gamma. J BIOL CHEM 1998, 273:1855-1858.

13. Lehmann J, Lenhard J, Oliver B, Ringold G, Kliewer S: Peroxisome proliferator-activated receptors alpha and gamma are activated by indomethacin and other non-steroidal anti-inflammatory drugs. J BIOL CHEM 1997, 272:3406-3410.

14. Ricote M, Li A, Willson T, Kelly C, Glass C: The peroxisome proliferatoractivated receptor-gamma is a negative regulator of macrophage activation. NATURE 1998, 391:79-82.

15. Chawla A, Barak Y, Nagy L, Liao D, Tontonoz P, Evans R: PPAR-gamma dependent and independent effects on macrophage-gene expression in lipid metabolism and inflammation. NAT MED 2001, 7:48-52.

16. Szanto A, Nagy L: The many faces of PPARgamma: anti-inflammatory by any means? IMMUNOBIOLOGY 2008, 213:789-803.

17. Yan C, Du H: Alveolus formation: what have we learned from genetic studies? J APPL PHYSIOL 2004, 97:1543-1548.

18. Asada K, Sasaki S, Suda T, Chida K, Nakamura H: Antiinflammatory roles of peroxisome proliferator-activated receptor gamma in human alveolar macrophages. AM J RESP CRIT CARE 2004, 169:195-200.

19. Reddy R, Keshamouni V, Jaigirdar S, Zeng X, Leff T, Thannickal V, Standiford TJ: Deactivation of murine alveolar macrophages by peroxisome proliferator-activated receptor-gamma ligands. Am J PhysiolLung C 2004, 286:L613-L619.

20. Soehnlein $\mathrm{O}$, Lindbom L: Phagocyte partnership during the onset and resolution of inflammation. NAT REV IMMUNOL 2010, 10:427-439.

21. Aronoff D, Serezani C, Carstens J, Marshall T, Gangireddy S, PetersGolden M, Reddy RC: Stimulatory Effects of Peroxisome ProliferatorActivated Receptor-gamma on Fcgamma Receptor-Mediated Phagocytosis by Alveolar Macrophages. In PPAR RES. Volume 2007. Hindawi Publishing Corporation; 2007.

22. Kintscher U, Wakino S, Bruemmer D, Goetze S, Graf K, Hsueh W, Law RE: TGF-beta(1) induces peroxisome proliferator-activated receptor gamma1 and gamma2 expression in human THP-1 monocytes. BIOCHEM BIOPH RES CO 2002, 297:794-799.

23. Momoi A, Murao K, Imachi H, Ishida T, Cao W, Sato M, Takahara J: Inhibition of monocyte chemoattractant protein-1 expression in cytokine-treated human lung epithelial cells by thiazolidinedione. CHEST 2001, 120:1293-1300

24. Wang A, Dai X, Luu B, Conrad DJ: Peroxisome proliferator-activated receptor-gamma regulates airway epithelial cell activation. AM J RESP CELL MOL 2001, 24:688-693.

25. Hetzel M, Walcher D, Grub M, Bach H, Hombach V, Marx N: Inhibition of MMP-9 expression by PPARgamma activators in human bronchial epithelial cells. THORAX 2003, 58:778-783.

26. Culver D, Barna B, Raychaudhuri B, Bonfield T, Abraham S, Malur A, Farver C, Kavuru M, Thomassen M: Peroxisome proliferator-activated receptor gamma activity is deficient in alveolar macrophages in pulmonary sarcoidosis. AM J RESP CELL MOL 2004, 30:1-5.

27. Barna B, Culver D, Abraham S, Malur A, Bonfield T, John N, Farver C, Drazba J, Raychaudhuri B, Kavuru M, et al: Depressed peroxisome proliferator-activated receptor gamma (PPARgamma) is indicative of severe pulmonary sarcoidosis: possible involvement of interferon gamma (IFN-gamma). SARCOIDOSIS VASC DIF 2006, 23:93-100.

28. Smith $M$, Standiford T, Reddy R: PPARs in alveolar macrophage biology. PPAR RES 2007, 2007.

29. Belvisi M, Hele D, Birrell M: Peroxisome proliferator-activated receptor gamma agonists as therapy for chronic airway inflammation. EUR J PHARMACOL 2006, 533:101-109.

30. Lee S, Kang E, Hur G, Jung K, Jung H, Lee S, Kim J, Shin C, In K, Kang K, et al: Peroxisome proliferator-activated receptor-gamma inhibits 
cigarette smoke solution-induced mucin production in human airway epithelial (NCl-H292) cells. Am J Physiol-Lung C 2006, 291:L84-L90.

31. Genovese T, Cuzzocrea S, Di Paola R, Mazzon E, Mastruzzo C, Catalano P, Sortino M, Crimi N, Caputi A, Thiemermann C, et al: Effect of rosiglitazone and 15-deoxy-Delta12,14-prostaglandin $\mathrm{J} 2$ on bleomycin-induced lung injury. EUR RESPIR J 2005, 25:225-234.

32. Spears M, McSharry C, Thomson NC: Peroxisome proliferator-activated receptor-gamma agonists as potential anti-inflammatory agents in asthma and chronic obstructive pulmonary disease. CLIN EXP ALLERGY 2006, 36:1494-1504.

33. Milam J, Keshamouni V, Phan S, Hu B, Gangireddy S, Hogaboam C, Standiford T, Thannickal V, Reddy RC: PPAR-gamma agonists inhibit profibrotic phenotypes in human lung fibroblasts and bleomycininduced pulmonary fibrosis. Am J Physiol-Lung C 2008, 294:L891-L901.

34. Babaev V, Yancey P, Ryzhov S, Kon V, Breyer M, Magnuson M, Fazio S, Linton M: Conditional knockout of macrophage PPARgamma increases atherosclerosis in C57BL/6 and low-density lipoprotein receptor-deficient mice. ARTERIOSCL THROM VAS 2005, 25:1647-1653.

35. Akiyama T, Sakai S, Lambert G, Nicol C, Matsusue K, Pimprale S, Lee Y, Ricote M, Glass C, Brewer HJ, et al: Conditional disruption of the peroxisome proliferator-activated receptor gamma gene in mice results in lowered expression of $A B C A 1, A B C G 1$, and apoE in macrophages and reduced cholesterol efflux. MOL CELL BIOL 2002, 22:2607-2619.

36. Chatterjee VK: Resistance to thyroid hormone, and peroxisomeproliferator-activated receptor gamma resistance. BIOCHEM SOC T 2001, 29:227-231.

37. Tan G, Savage D, Fielding B, Collins J, Hodson L, Humphreys S, O'Rahilly S, Chatterjee K, Frayn K, Karpe F: Fatty acid metabolism in patients with PPARgamma mutations. J CLIN ENDOCR METAB 2008, 93:4462-4470.

38. Boiani R, Cinti S, Savage D, Vidal-Puig A, O'Rahilly S: Abdominal subcutaneous adipose tissue morphology in a patient with a dominantnegative mutation (P467L) in the nuclear receptor peroxisome proliferator-activated receptor-gamma (PPARG) gene. NUTR METAB CARDIOVAS 2010, 20:e11-12.

39. Kobayashi M, Thomassen M, Rambasek T, Bonfield T, Raychaudhuri B, Malur A, Winkler A, Barna B, Goldman S, Kavuru MS: An inverse relationship between peroxisome proliferator-activated receptor gamma and allergic airway inflammation in an allergen challenge model. ANN ALLERG ASTHMA IM 2005, 95:468-473.

40. Perez A, van Heeckeren A, Nichols D, Gupta S, Eastman J, Davis P: Peroxisome proliferator-activated receptor-gamma in cystic fibrosis lung epithelium. Am J Physiol-Lung C 2008, 295:303-313.

41. Stoeger T, Reinhard C, Takenaka S, Schroeppel A, Karg E, Ritter B, Heyder J, Schulz H: Instillation of six different ultrafine carbon particles indicates a surface area threshold dose for acute lung inflammation in mice. ENVIRON HEALTH PERSP 2006, 114:328-333.

42. Ganguly K, Upadhyay S, Irmler M, Takenaka S, Pukelsheim K, Beckers J, Hamelmann E, Schulz H, Stoeger T: Pathway focused protein profiling indicates differential function for IL-1B, -18 and VEGF during initiation and resolution of lung inflammation evoked by carbon nanoparticle exposure in mice. PART FIBRE TOXICOL 2009, 6.

43. Jacobsen N, Moller P, Jensen K, Vogel U, Ladefoged O, Loft S, Wallin H: Lung inflammation and genotoxicity following pulmonary exposure to nanoparticles in ApoE-/- mice. PART FIBRE TOXICOL 2009, 6.

44. Nel A, Xia T, Madler L, Li N: Toxic potential of materials at the nanolevel. SCIENCE 2006, 311:622-627.

45. Duffin R, Mills N, Donaldson K: Nanoparticles-a thoracic toxicology perspective. YONSEI MED J 2007, 48.

46. Surazynski A, Jarzabek K, Miltyk W, Wolczynski S, Palka J: Estrogendependent regulation of PPAR-gamma signaling on collagen biosynthesis in adenocarcinoma endometrial cells. NEOPLASMA 2009, 56:448-454.

47. Ueki S, Oguma M, Usami A, Kamada Y, Kato H, Kamada R, Takeda M, Ito W, Tanigai T, Kayaba $H$, et al: Regulation of peroxisome proliferator-activated receptor-gamma expression in human eosinophils by estradiol. INT ARCH ALLERGY IMM 2009, 149:51-56.

48. Andre E, Stoeger T, Takenaka S, Bahnweg M, Ritter B, Karg E, Lentner B, Reinhard C, Schulz H, Wjst M: Inhalation of ultrafine carbon particles triggers biphasic pro-inflammatory response in the mouse lung. EUR RESPIR J 2006, 28:275-285.
49. Barroso I, Gurnell M, Crowley V, Agostini M, Schwabe J, Soos M, Maslen G, Williams T, Lewis $\mathrm{H}$, Schafer A, et al: Dominant negative mutations in human PPARgamma associated with severe insulin resistance, diabetes mellitus and hypertension. Nature 1999, 402:880-883.

50. Gray S, Dalla Nora E, Backlund E, Manieri M, Virtue S, Noland R, O'Rahilly S, Cortright R, Cinti S, Cannon B, et al: Decreased brown adipocyte recruitment and thermogenic capacity in mice with impaired peroxisome proliferator-activated receptor (P465L PPARgamma) function. ENDOCRINOLOGY 2006, 147:5708-5714.

51. Brown R, Walters D, Greenberg R, Mitzner W: A method of endotracheal intubation and pulmonary functional assessment for repeated studies in mice. J APPL PHYSIOL 1999, 87:2362-2365.

52. Kodavanti U, Schladweiler MC, Schladweiler M, Ledbetter AD, AD L, Hauser R, Christiani D, McGee J, Richards J, Costa DL: Temporal association between pulmonary and systemic effects of particulate matter in healthy and cardiovascular compromised rats. J TOXICOL ENV HEAL A 2002, 65:1545-1569.

doi:10.1186/1743-8977-8-28

Cite this article as: Götz et al:: Carbon-nanoparticle-triggered acute lung inflammation and its resolution are not altered in PPAR $\gamma$-defective (P465L) mice. Particle and Fibre Toxicology 2011 8:28.

\section{Submit your next manuscript to BioMed Central and take full advantage of:}

- Convenient online submission

- Thorough peer review

- No space constraints or color figure charges

- Immediate publication on acceptance

- Inclusion in PubMed, CAS, Scopus and Google Scholar

- Research which is freely available for redistribution

Submit your manuscript at www.biomedcentral.com/submit
Ciomed Central 